\begin{tabular}{|c|c|c|}
\hline \multirow{3}{*}{$\begin{array}{r}\text { Case Reports in } \\
\text { Gastroenterology }\end{array}$} & \multirow{2}{*}{\multicolumn{2}{|c|}{ Case Rep Gastroenterol 2014;8:169-174 }} \\
\hline & & \\
\hline & $\begin{array}{l}\text { DOI: } 10.1159 / 000363375 \\
\text { Publisned onIIne: Ivay 14, } 2014\end{array}$ & $\begin{array}{l}\text { ○ 2014 S. Karger AG, Basel } \\
\text { 1662-0631/14/0082-0169 } \$ 39.50 / 0 \\
\text { www.karger.com/crg }\end{array}$ \\
\hline & \multicolumn{2}{|c|}{$\begin{array}{l}\text { This is an Open Access article licensed under the terms of the Creative Commons } \\
\text { Attribution-NonCommercial } 3.0 \text { Unported license (CC BY-NC) (www.karger.com/OA } \\
\text { license), applicable to the online version of the article only. Distribution permitted for non } \\
\text { commercial purposes only. }\end{array}$} \\
\hline
\end{tabular}

\title{
Cystic Liver Infection after Living Donor Liver Transplantation: A Case Report
}

\author{
Kensuke Kudou Mizuki Ninomiya Tomohiro Iguchi \\ Norifumi Harimoto Shinji Itoh Noboru Harada Kazuki Takeishi \\ Yo-ichi Yamashita Tomoharu Yoshizumi Yuji Soejima Tetsuo Ikeda \\ Ken Shirabe Yoshihiko Maehara \\ Department of Surgery and Science, Graduate School of Medical Sciences, Kyushu \\ University, Fukuoka, Japan
}

\section{Key Words}

Cystic liver infection · Living donor liver transplantation · Percutaneous drainage · Primary sclerosing cholangitis

\begin{abstract}
There are no reports of cystic liver infection after liver transplantation. Herein, we report a rare case of cystic liver graft infection after living donor liver transplantation (LDLT). The patient was a 24-year-old man with primary sclerosing cholangitis who underwent right lobe graft LDLT. Preoperative abdominal computed tomography (CT) revealed a liver cyst at segment 8 of the donor liver. Biliary reconstruction was performed with hepaticojejunostomy. The postoperative course was uneventful until the patient developed a high fever and abdominal pain 15 months after LDLT. Abdominal contrast CT revealed abscess formation. Percutaneous drainage of the cyst was performed and purulent liquid was drained. The fever gradually subsided after treatment. On follow-up CT, the size of the infected liver cyst was decreased. Clinicians should be aware of the potential for cystic liver infection when using grafts with liver cysts, particularly when biliary reconstruction is performed with hepaticojejunostomy.

(c) 2014 S. Karger AG, Basel
\end{abstract}


Kudou et al.: Cystic Liver Infection after Living Donor Liver Transplantation: A Case Report

\section{Introduction}

Cystic liver lesions are often found during the evaluation of liver donors for transplantation. Several cases of living donor liver transplantation (LDLT) using grafts with liver cysts have been reported. Recently, a few cases of polycystic donor liver allografts from cadaveric donors have been reported, with no cyst-related complications [1, 2]. Furthermore, successful cases of LDLT using liver grafts with multiple large cysts have been reported [3]. One possible problem with the use of cystic liver grafts is the risk of infection, as cystic infection after surgery has been reported in other contexts. However, there have been no reports of cystic liver infection after liver transplantation. Herein, we report a rare case of cystic liver graft infection after LDLT.

\section{Case Report}

The patient was a 24-year-old man with primary sclerosing cholangitis (PSC). As his liver function gradually deteriorated and exacerbation of esophageal varices and portal hypertension required repeated endoscopic treatment, he underwent right lobe graft LDLT in February 2012. The donor was the recipient's 48-year-old mother. Preoperative abdominal computed tomography (CT) revealed a liver cyst $20 \times 26 \mathrm{~mm}$ in diameter at segment 8 of the donor liver, which showed no specific signs of infection (fig. 1). The right lobe graft without the middle hepatic vein was implanted. Biliary reconstruction was performed with hepaticojejunostomy. Hepatic arterial reconstruction was performed between the right hepatic artery of the recipient and the left hepatic artery of the donor using a microscope. Postoperative Doppler ultrasound confirmed good hepatic arterial flow.

The clinical course immediately after transplantation progressed without significant surgical complications. Immunosuppression was maintained with mycophenolate mofetil (Cellcept ${ }^{\circledR}$; Chugai Pharmaceutical Co. Ltd., Tokyo, Japan), tacrolimus (Prograf ${ }^{\circledR}$; Astellas, Tokyo, Japan) and prednisolone. The doses of mycophenolate mofetil and prednisolone were gradually decreased. The tacrolimus dose was adjusted to a trough concentration of 5-10 $\mathrm{ng} / \mathrm{ml}$. The postoperative course was uneventful until the patient developed a high fever and abdominal pain 15 months after LDLT. Laboratory data were as follows: white blood cell count $23,930 / \mu \mathrm{l}$, total bilirubin $1.3 \mathrm{mg} / \mathrm{dl}$, serum aspartate transaminase $20 \mathrm{IU} / \mathrm{l}$, serum alanine aminotransferase $23 \mathrm{IU} / \mathrm{l}$ and serum C-reactive protein (CRP) $17.58 \mathrm{mg} / \mathrm{dl}$. Abdominal contrast CT revealed that the size of the pre-existing segment 8 cyst had increased to $28 \times 48 \mathrm{~mm}$ in diameter. Furthermore, a low-density area around the cyst and thickening of the partition wall had appeared. Therefore, abscess formation was suspected (fig. 2).

The patient was hospitalized and received antibiotic treatment. The first choice of antibiotic was $4.5 \mathrm{~g}$ tazobactam/piperacillin (Zosyn ${ }^{\circledR}$; Taisho Toyama Pharmaceutical Co. Ltd., Tokyo, Japan) thrice daily intravenously. In addition, percutaneous drainage of the cyst was performed. A 7-Fr pigtail catheter was used to puncture the cyst, through which $25 \mathrm{ml}$ of purulent liquid was drained (fig. 3). Klebsiella pneumoniae was detected in the drainage culture. The patient's fever gradually subsided after treatment. On follow-up CT 7 days after hospitalization, the size of the infected liver cyst was decreased to $23 \times 31 \mathrm{~mm}$, but the thickening of the cyst wall remained (fig. 4a). The laboratory data improved, with a white blood cell count of $12,780 / \mu \mathrm{l}$ and a CRP of $1.81 \mathrm{mg} / \mathrm{dl}$. In addition, the fever and abdominal pain disappeared, thus the patient was discharged on day 13 after hospitalization. Oral administration of Cravit was continued for 28 days after discharge. On follow-up CT 54 days 
Kudou et al.: Cystic Liver Infection after Living Donor Liver Transplantation: A Case Report

after drainage, the size of the liver cyst was remarkably decreased (fig. 4b). The patient's symptoms have not recurred to date.

\section{Discussion}

The prevalence of congenital liver cysts in the general population ranges from 2 to $4 \%$, with the majority found in patients aged 40-60 years [4]. The female:male ratio has been cited as 5.25:1 [5]. Solitary cysts involve the right lobe twice as often as the left lobe and very rarely arise in the falciform ligament [6]. Liver cysts are usually asymptomatic; therefore, few cases of liver cysts are indicated for treatment. However, some liver cysts induce complications such as hemorrhage [7, 8], rupture [9], or infection $[10,11]$ in certain conditions. Representative routes of cystic liver infection are the bile duct or portal system, direct spread of an adjacent infection, or trauma [11]. Gram-negative bacilli (Escherichia coli, K. pneumoniae and others) are representative pathogens of cystic liver infection. Detection of enterobacteria in the pus suggests infection through the bile duct.

Several cases of cystic liver infection after surgery including choledochojejunostomy have been reported. The incidence of cholangitis after pancreaticoduodenectomy ranges from 14.3 to $18.9 \%$ [12]. The cause of cholangitis after pancreaticoduodenectomy is proposed to be loss of the backflow prevention function of the duodenal papilla.

Although some cases of liver transplantation using grafts with liver cysts have been reported, cases of cystic liver infection are very rare. Sakamoto et al. [13] reported that 15 recipients who received grafts with cystic lesions (12 left-sided lobes and 3 right-sided lobes) had no cyst-related complications. Recently, Amano et al. [3] reported that liver grafts with multiple large cysts are transplantable with no cyst-related complications such as infection, hemorrhage or rupture. Therefore, donors with cystic lesions are generally considered to be acceptable as liver donors. However, hepatic cyst infection occurred in our case. In the adult LDLT procedure, choledochocholedochostomy is usually performed for biliary reconstruction. Therefore, the backflow prevention function of the duodenal papilla is usually preserved. On the other hand, in some cases (PSC, child transplantation and others), hepaticojejunostomy is performed for biliary reconstruction. In the present case of a PSC patient, hepaticojejunostomy was performed because the bile ducts of PSC patients are at risk of carcinogenesis. In addition, K. pneumoniae was detected in the drainage culture. Therefore, retrograde infection from the intestinal tract secondary to hepaticojejunostomy was the most likely cause in our case. Although LDLT using grafts with hepatic cysts is safely performed in most cases, we suggest that hepaticojejunostomy could be a risk factor for hepatic cyst infection.

Harris et al. [14] reported that among 111 patients with adult polycystic kidney disease who underwent renal transplantation, the incidence of symptomatic hepatic cyst disease was $15 \%$, with 3 deaths due to hepatic cyst infection. This report indicates that immunosuppression therapy could represent an additional risk factor for cystic liver infection.

In conclusion, although LDLT using grafts with hepatic cysts is performed safely, hepaticojejunostomy could be a risk factor for cyst infection. This risk should be considered in cases of LDLT using grafts with liver cysts and hepaticojejunostomy. 


\begin{tabular}{l|l}
\hline \multicolumn{2}{l}{ Case Rep Gastroenterol 2014;8:169-174 } \\
\hline DOI: $10.1159 / 000363375$ & $\begin{array}{l}\text { C 2014 S. Karger AG, Basel } \\
\text { www.karger.com/crg }\end{array}$ \\
\hline
\end{tabular}

Kudou et al.: Cystic Liver Infection after Living Donor Liver Transplantation: A Case Report

\section{References}

1 Glanemann M, Langrehr JM, Stange B, et al: Polycystic liver grafts for orthotopic liver transplantation. Transplant Proc 2000;32:134-135.

2 Panis Y, Massault PP, Sarfati PO, et al: Emergency liver retransplantation using a polycystic donor liver. Transplantation 1994;57:1672-1674.

3 Amano H, Tashiro H, Itamoto T, et al: Successful living donor left liver transplantation by using liver graft with multiple large cysts. Transplant Proc 2009;41:3923-3926.

4 Gaines PA, Sampson MA: The prevalence and characterization of simple hepatic cysts by ultrasound examination. Br J Radiol 1989;62:335-337.

5 Flagg RS, Robinson DW: Solitary nonparasitic hepatic cysts. Report of oldest known case and review of the literature. Arch Surg 1967;95:964-973.

6 Enterline DS, Rauch RE, Silverman PM, et al: Cyst of the falciform ligament of the liver. AJR Am J Roentgenol 1984;142:327-328.

7 Yoshida H, Onda M, Tajiri T, et al: Intracystic hemorrhage of a simple hepatic cyst. Hepatogastroenterology 2002;49:1095-1097.

$>8$ Takahashi G, Yoshida H, Mamada Y, et al: Intracystic hemorrhage of a large simple hepatic cyst. J Nippon Med Sch 2003;70:515-518.

9 Klingler PJ, Bodner E, Schwelberger HG, et al: Late complication after laparoscopic fenestration of a liver cyst. Surg Laparosc Endosc 1998;8:76-77.

10 Shoji F, Kitamura M, Shirabe K, et al: Infected hepatic cyst in a patient with multiple hepatic cysts: report of a case diagnosed by change of ultrasonographic findings. Eur J Gastroenterol Hepatol 2000;12:703-705.

11 Ishii K, Yoshida H, Taniai N, et al: Infected hepatic cyst treated with percutaneous transhepatic drainage. J Nippon Med Sch 2009;76:160-164.

12 Fujiwara K, Nakamura M, Tanaka M, et al: Two cases of infected liver cyst following pylorus-preserving pancreatoduodenectomy. J Jpn Surg Assoc 2009;71:2096-2099.

-13 Sakamoto S, Nosaka S, Shigeta T, et al: Living donor liver transplantation using grafts with hepatic cysts. Liver Transpl 2012;18:1415-1420.

14 Harris RA, Gray DW, Britton BJ, et al: Hepatic cystic disease in an adult polycystic kidney disease transplant population. Aust N Z J Surg 1996;66:166-168.

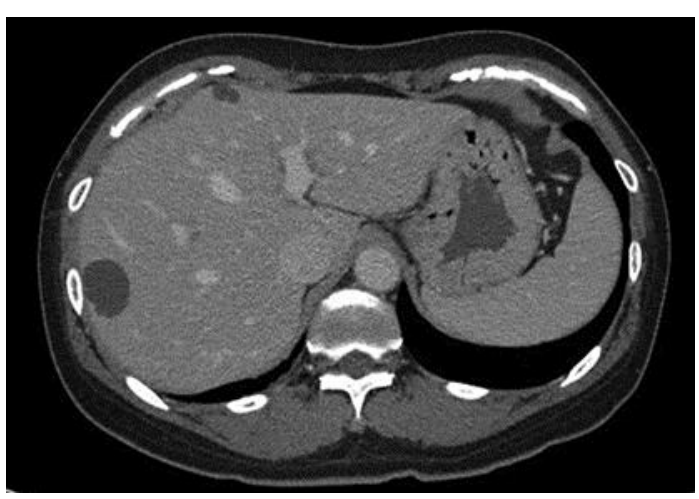

Fig. 1. Preoperative abdominal CT of the donor revealed a liver cyst of $20 \times 26 \mathrm{~mm}$ in diameter at segment 8 , which showed no specific signs of infection. 
Kudou et al.: Cystic Liver Infection after Living Donor Liver Transplantation: A Case Report

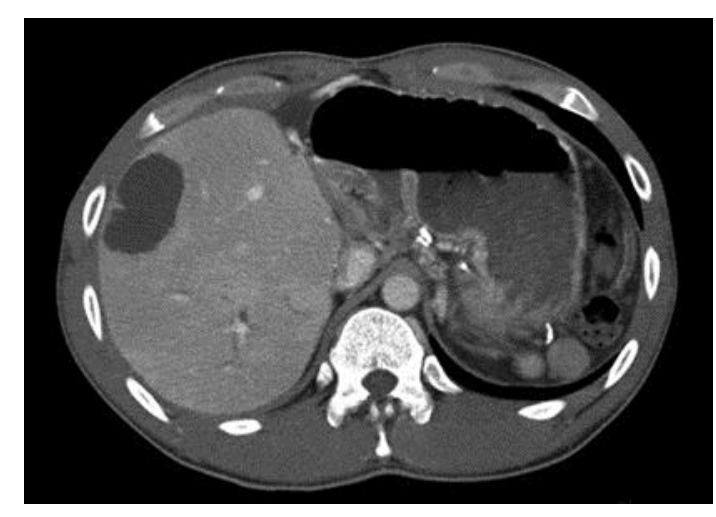

Fig. 2. Abdominal contrast CT 15 months after LDLT. The size of the pre-existing cyst in segment 8 had increased to $28 \times 48 \mathrm{~mm}$. Furthermore, a low-density area around the cyst and thickening of the partition wall had appeared. Therefore, abscess formation was suspected.

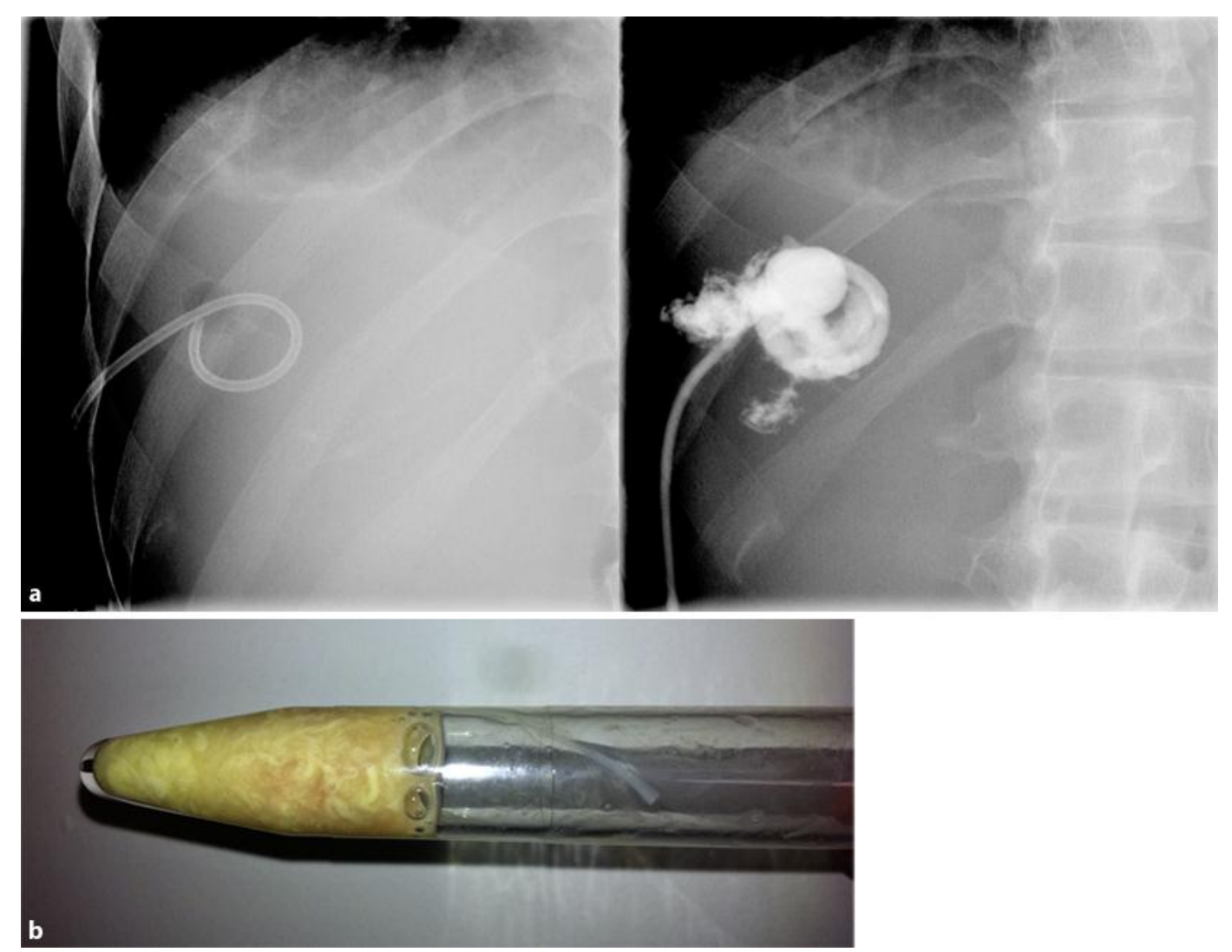

Fig. 3. Percutaneous drainage of the cyst was performed. A 7-Fr pigtail catheter was used to puncture the cyst (a) and drain the purulent liquid (b). 

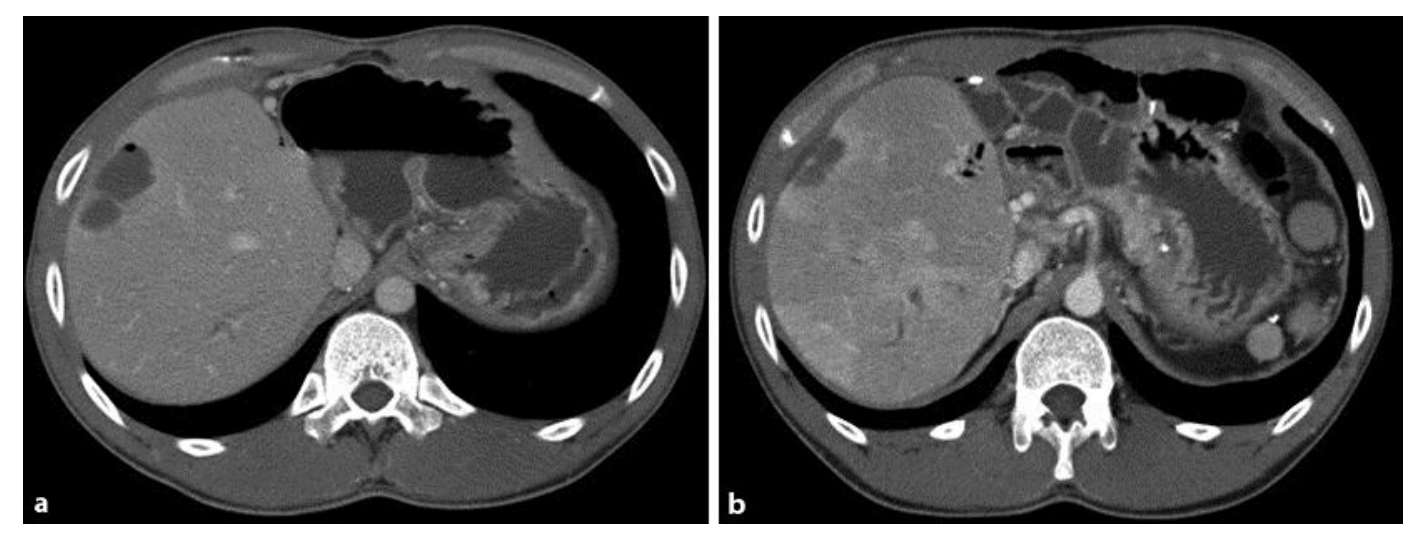

Fig. 4. Follow-up CT after percutaneous drainage and antibiotic treatment. The size of the infected liver cyst had decreased to $23 \times 31 \mathrm{~mm}$, but the thickening of the cyst wall remained (a). On follow-up CT 54 days after drainage, the size of the liver cyst was remarkably decreased (b). 